\title{
Attachment properties of blue mussel (Mytilus edulis L.) byssus threads on culture-based artificial collector substrates
}

\author{
M. Brenner ${ }^{\mathrm{a}, \mathrm{b}, \mathrm{c}, *}$, B.H. Buck $\mathrm{B}^{\mathrm{a}, \mathrm{c}, \mathrm{d}}$ \\ a Alfred Wegener Institute for Polar and Marine Research (AWI), Am Handelshafen 12, 27570 Bremerhaven, Germany \\ b Jacobs University Bremen, Campus Ring 1, 28759 Bremen, Germany \\ ' Institute for Marine Resourses (IMARE), Klußmannstraße 1, 27570 Bremerhaven, Germany \\ d University of Applied Sciences Bremerhaven, An der Karlstadt 8, 27568 Bremerhaven, Germany
}

\section{A R T I C L E I N F O}

\section{Article history:}

Received 25 May 2009

Accepted 9 February 2010

\section{Keywords:}

Spat collectors

Offshore aquaculture

Offshore wind farms

Mytilus edulis

Dislodgement

\begin{abstract}
A B S T R A C T
The attachment strength of blue mussels (Mytilus edulis) growing under exposed conditions on 10 different artificial substrates was measured while assessing microstructure of the applied substrate materials. Fleece-like microstructure attracted especially mussel larvae, however, most settled individuals lost attachment on this type of microstructure with increasing size during the time of experiment. Substrates with thick filaments and long and fixed appendices were less attractive to larvae but provided a better foothold for juvenile mussels as shown by the results of the dislodgement trials. In addition these appendices of substrates could interweave with the mussels, building up a resistant mussel/substrate conglomerate. Our results show that a mussel byssus apparatus can withstand harsh conditions, if suitable substrates are deployed. Depending on cultivation aims (seed or market sized mussels) and cultivation method (one or two step cultivation), different collector types for larval attraction, good foothold and interweaving abilities or collectors combining these properties should be developed and applied. The study suggests that substrates need to be very precisely tailored according to the major environmental conditions. Furthermore, the results imply that a "one size fits all substrate" may not be the most cultureeffective approach, but, in the contrary, substrates need to be changed and modified according to the size of the mussel as they go through their different life cycle stages.
\end{abstract}

(c) 2010 Elsevier B.V. All rights reserved.

\section{Introduction}

Commercial fisheries and aquaculture in Europe have long been engaged in the farming of blue mussels (Mytilus edulis), a stable food source in this part of the world for many centuries (Smaal, 2002). The exploitation of natural mussel beds along the German North Sea coast has a long tradition (Kleinsteuber and Will, 1988). Since the 1950s a combined fishery-culture system has developed (Korringa, 1976), using the techniques described by Seaman and Ruth (1997). Juveniles are collected with dredges from natural intertidal mussel beds and transferred to licensed culture plots, where environmental conditions are suitable for growth and fattening. However, due to poor recruitment over the last several years in the Wadden Sea (Germany, Denmark and The Netherlands), research commenced in the year 2000 to investigate whether or not suspended culture techniques could be used to obtain seed mussels in an inshore area

\footnotetext{
* Corresponding author at: Present adress: Blue Bioindustry, Institute for Marine Resources (IMARE), Klußmannstraße 1, 27570 Bremerhaven, Germany. Tel.: +49 47192419 2204; fax: +49 471924192210.

E-mail address: Matthias.Brenner@imare.de (M. Brenner).
}

of the Jade estuary (Walter and Liebezeit, 2001, 2003) as well as in offshore sites of the coastal sea and the economic exclusive zone within the German Bight (Buck, 2007; Walter et al., submitted for publication).

The development of European mussel farming has taken place nearly exclusively in protected nearshore waters and estuarine habitats. In Germany, however, sheltered locations are rare and because of tremendous stakeholder conflicts the advancement of coastal mussel culture has been rather stagnant (CWSS, 2008). As a consequence, aquaculture activities have tended to move to more exposed offshore sites (Ryan, 2005). It is widely believed that the commercialization of mariculture in the open ocean has enormous future economic potential (Stickney, 1998; Bridger and Costa-Pierce, 2003; Buck et al., 2004). In 1998, the University of New Hampshire initiated the Open Ocean Aquaculture Demonstration Project to investigate the commercial potential of environmentally responsible seafood production, employment opportunities, engineering solutions and operational methodologies of offshore aquaculture (Bucklin and Howell, 1998). As a subproject Langan and Horton (2003) tested the biological and commercial feasibility of $M$. edulis cultivation with $120 \mathrm{~m}$ long submerged test facilities $10 \mathrm{~km}$ off the coast of Portsmouth (New Hampshire). 
Table 1

Compilation of parameters investigated having an effect on larval settlement and post-mortality (modified after Filgueira et al., 2007).

\begin{tabular}{|c|c|c|}
\hline Characteristics & Parameter & Data resources \\
\hline Composition & $\begin{array}{l}\text { Surface free energy } \\
\text { Wettability } \\
\text { Polarity } \\
\text { Associated fouling }\end{array}$ & $\begin{array}{l}\text { Nishida et al. (2003) } \\
\text { Alfred et al. (2005) } \\
\text { Hansen and Waite (1991) } \\
\text { Alfaro et al. (2006) }\end{array}$ \\
\hline Structural properties & $\begin{array}{l}\text { Surface area } \\
\text { Thickness of filaments }\end{array}$ & $\begin{array}{l}\text { Walter and Liebezeit (2003) } \\
\text { Alfaro and Jeffs (2003) and Lekang et al. (2003) }\end{array}$ \\
\hline Post-mortality & $\begin{array}{l}\text { Hydrodynamic disturbance } \\
\text { Competition for space and food } \\
\text { Predation } \\
\text { Intraspecific competition }\end{array}$ & $\begin{array}{l}\text { Eckman (1987) and McShane and Nylor (1995) } \\
\text { Guiñez and Castilla (1999) and Guiñez (2005) } \\
\text { Schiel (2004) and Morrisey et al. (2006) } \\
\text { Filgueira et al. (2007) }\end{array}$ \\
\hline \multirow[t]{4}{*}{$\begin{array}{l}\text { Characteristics of spat } \\
\text { collector ropes }\end{array}$} & $\begin{array}{l}\text { Strength of seed attachment (visual judgement only) } \\
\text { Structural complexity to reduce predation }\end{array}$ & $\begin{array}{l}\text { Lekang et al. (2003) } \\
\text { Moreno (1995), Filgueira et al. (2007), Walters } \\
\text { and Wethey (1996) and Frandsen and Dolmer } \\
(2002)\end{array}$ \\
\hline & High density in ropes with filamentous loops & Filgueira et al. (2007) \\
\hline & High yield in ropes with non-filamentous loops & Filgueira et al. (2007) \\
\hline & Combination of spat collecting devices until harvesting & Bomo et al. (1998) \\
\hline
\end{tabular}

Recently, a new stakeholder is expanding far off the coast-the offshore wind farm industry. Within this new development the concept of combining renewable energy production with the cultivation of different organisms was born and a synergistic resource use in the form of aquaculture and offshore wind farming has been intensively investigated (for review see Buck et al., 2008). This requires a suspended culture technique where mussels settle on artificial substrates, commonly called collectors, attached to a horizontal floating or submerged longline and hanging vertically in the water column (Hickman, 1992). Unfortunately, offshore sites in the German Bight are exposed to high waves and strong currents (Becker et al., 1992), requiring techniques and a system design that can withstand these conditions (Langan and Horton, 2003; Buck, 2007) while at the same time support settling and good growth of cultivated mussels as well as preventing detachment and subsequent loss. Settlement of mussels on substrates is defined by Connell (1985) as being the point when larvae first take up a durable residence and, if necessary during inhospitable conditions, allowing a detachment and a subsequent second residence on another substrate (Alfaro et al., 2006). Following the compilation by Filgueira et al. (2007) (Table 1) the attachment behaviour of mussel threads on a substratum is quite manifold and is affected by (1) the composition of material, (2) surface condition, (3) exposure to stress conditions and (4) type of spat collectors used for aquaculture. Furthermore, fouling organisms such as barnacles, bryozoans and seaweeds may increase mussel mortality by increasing the mussel's weight as well as its drag (Witman and Suchanek, 1984), which results in an increased risk of detachment by wave action and tidal currents.

Parameters which increase the hydrodynamic forces exerted on mussels will be important factors when considering mussel cultivation in offshore environments, since they will alter the probability

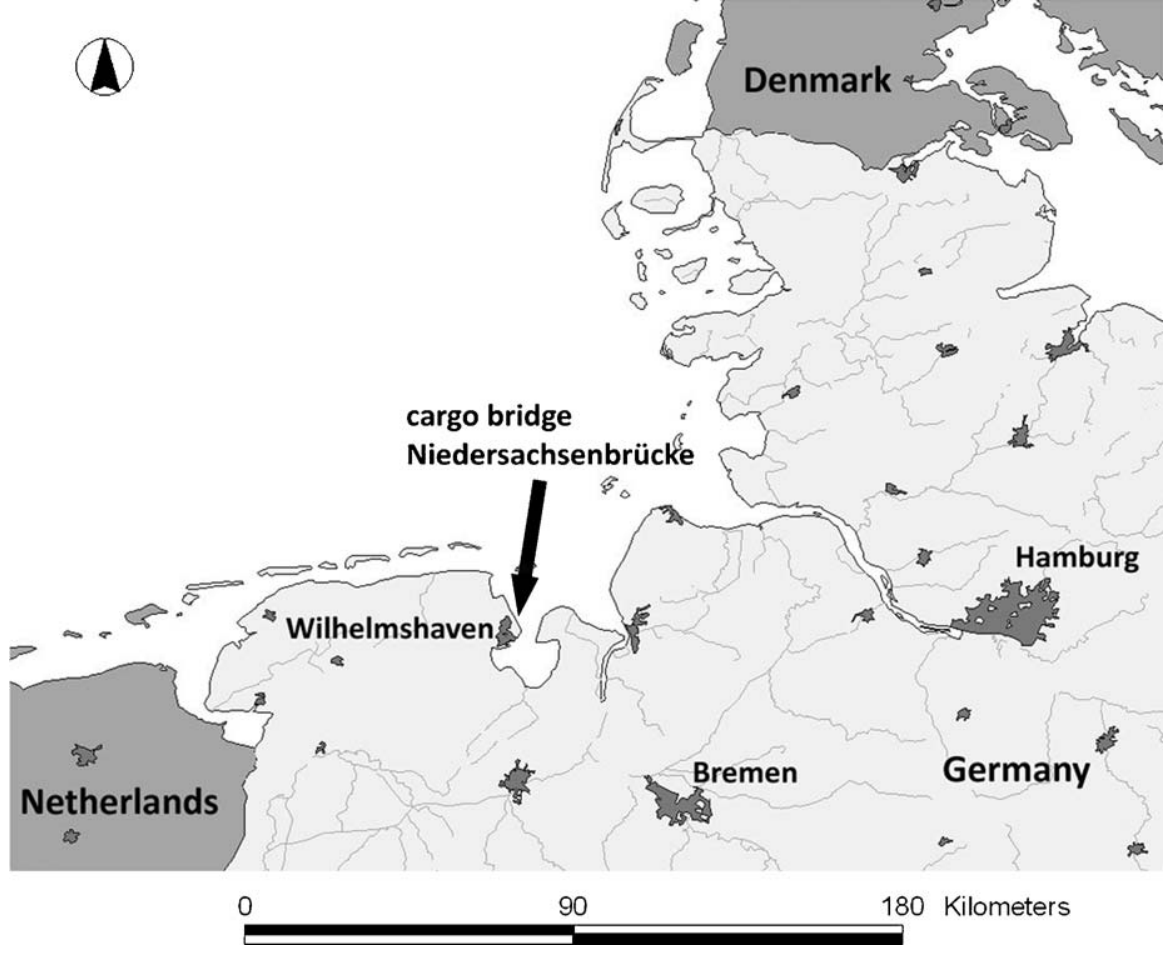

Fig. 1. Map of the German Bight showing the test site at the cargo bridge Niedersachsenbrücke near the city of Wilhelmshaven. 
that mussels will be dislodged. Thus, the survival of mussels is to a large extent dependent on their ability to form a strong attachment in order to withstand large forces imparted by wave shock and surge (Witman and Suchanek, 1984) as well as current velocity (Price, 1982; Bell and Gosline, 1997).

With the exception of studies by Walter and Liebezeit (2003) and Lekang et al. (2003) on aspects such as settlement success on different substrates, growth performance and shaking resistance (visually), the attachment and detachment strength of mussel threads on spat collectors in high energy environments has remained unexplored. The aim of this work is to gain insight into the attachment strength of mussels on various materials enabling them to withstand strong environmental conditions, for optimal cultivation at exposed sites. Therefore, we examine the effectivity of spat collectors under exposed conditions by investigating the following: (i) the attachment of mussel thread plaques on different materials, (ii) the number of threads mussels use to attach to a certain substrate, and (iii) the force necessary to dislodge the mussels from a given artificial substrate.

\section{Material and methods}

\subsection{Experimental configuration}

The experiments were conducted with cultivated blue mussels (M. edulis) settled on artificial spat collectors. These spat collectors originated from a testing area located in a high energy environment at the outer Jade estuary in the German Bight $\left(53^{\circ} 35^{\prime} 05.12^{\prime \prime} \mathrm{N}\right.$, $08^{\circ} 09^{\prime} 14.57^{\prime \prime}$, North Sea, Fig. 1). The test collector harnesses were suspended loose-hanging from a cargo bridge (Coal Cargo Bridge Niedersachsenbrücke of the Niedersachsen Ports GmbH \& Co. KG) approx. $1300 \mathrm{~m}$ off the coast in the vicinity of a waterway (Fig. 2a).

A total of 10 harnesses were hung below the jetty allowing a distance of $20 \mathrm{~m}$ between harnesses (Fig. 2b). Each harness consisted of a $20 \mathrm{~mm}$ polypropylene rope with an iron plate $(5 \mathrm{~kg})$ at its distal end, weighing down the substrates into the water column even at strong current velocities (Fig. 2c). The upper part of the harness was attached to a steel beam between the pillars of the bridge. The polypropylene ( $\mathrm{pp}$ ) rope was strengthened with two swirls and
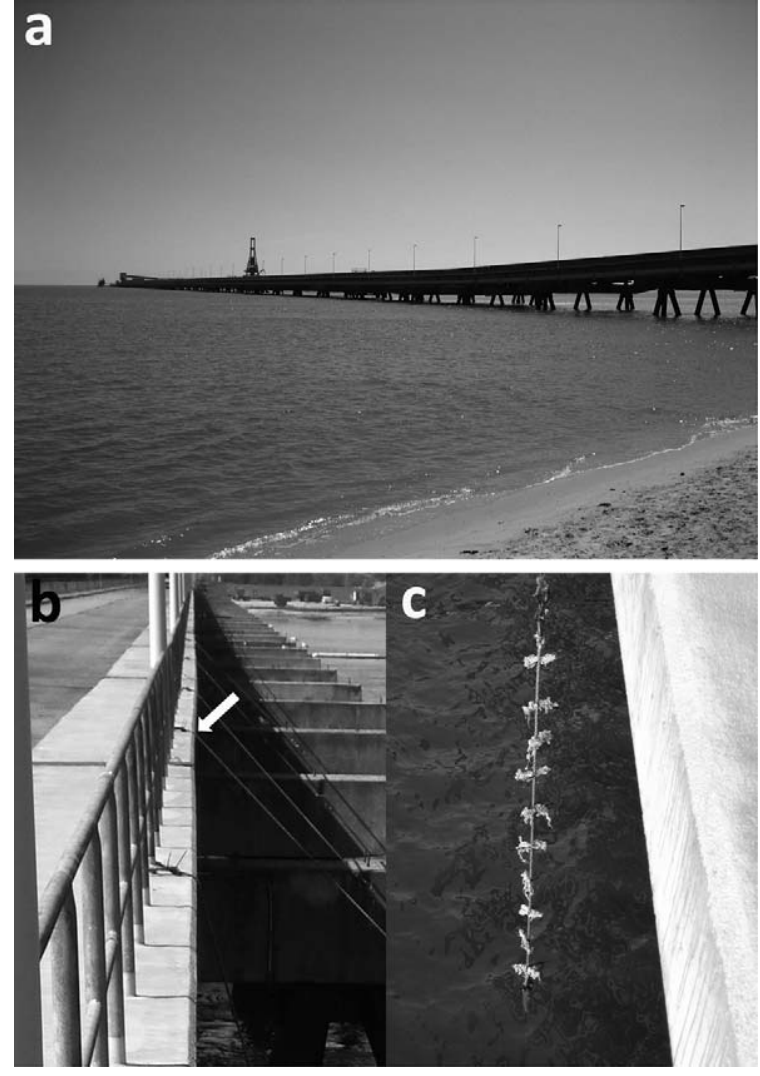

Fig. 2. (a) The $1300 \mathrm{~m}$ long cargo bridge at the Jade estuary, (b) harnesses attached to a steel beam, hanging between the pillars of the bridge (see white arrow), each of them consisting of (c) a $20 \mathrm{~mm}$ rope carrying substrate samples and a weight at the distal end.

shackles to prevent entanglement. The lower swirl was placed one meter above the mean high water ( $\mathrm{mHW}$ ) level to prevent corrosion and fouling. To insure that the cultivated mussels were submerged during the whole of the experiment, samples of artificial test col-

Table 2

Spat collector types used for this experiment.
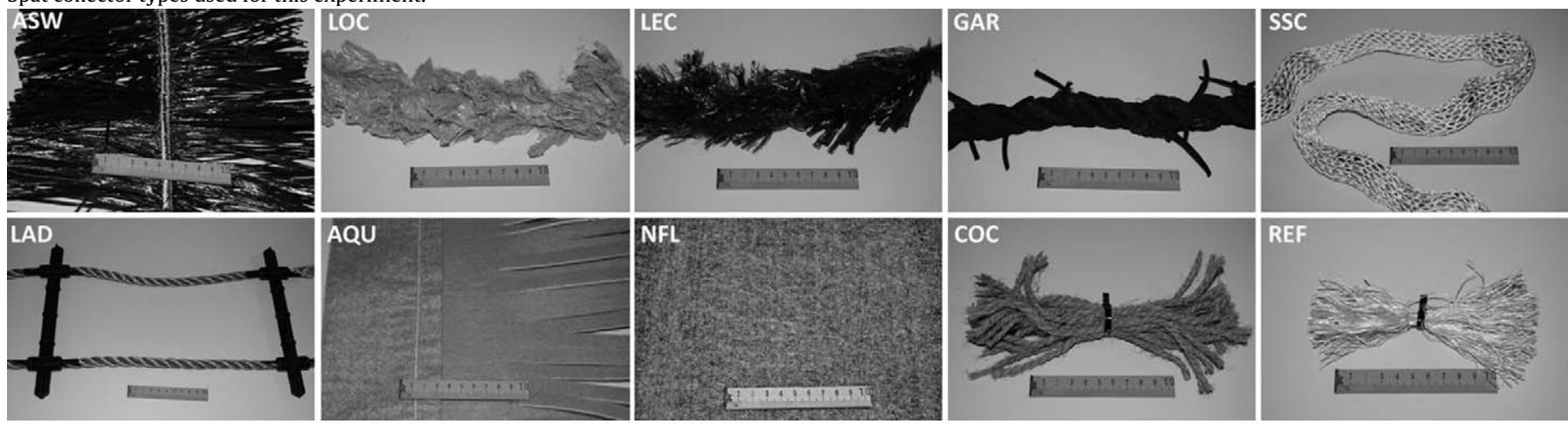

\begin{tabular}{|c|c|c|c|c|}
\hline No. & Shortcut & Name & Characteristics & Origin \\
\hline (1) & ASW & Artificial Seaweed & $10 \mathrm{~mm}$ nylon rope as back bone with $10 \mathrm{~cm}$ long pp-leaves attached at both sites & Japan \\
\hline$(2)$ & LOC & Leaded Christmas Tree & Extruded polypropylene with a straight trim, strands of lead in the center help sinking & New Zealand \\
\hline (3) & LEC & Looped Christmas Tree & Extruded polypropylene with a looped trim, strands of lead in the center help sinking & New Zealand \\
\hline (4) & GAR & Galician Rope & Rough surfaced nylon-pe ropes with strands & Spain \\
\hline (5) & SSC & Self-Sinking Collector & Polyester net formed as a tube, small stones help sinking & Norway \\
\hline (6) & LAD & Ladder Collector & $16 \mathrm{~mm}$ parallel running pp-ropes connected every $35 \mathrm{~cm}$ by a plastic bar & Norway \\
\hline (7) & AQU & Aquamats ${ }^{\circledR}$ & Strands of pp fleece material with ballast sleeve & USA \\
\hline$(8)$ & NFL & Naue ${ }^{\circledR}$ Fleece & pp fleece, cost-saving alternative to AQU & Germany \\
\hline (9) & $\mathrm{COC}$ & Coconut Rope & $24 \mathrm{~mm}$ rope of coconut fibres & India \\
\hline (10) & REF & Reference Collector & Bushy tufts of a unravelled $10 \mathrm{~mm}$ pp-rope & Germany \\
\hline
\end{tabular}


lectors were attached to the pp-rope from one to approximately three meters below mean low water ( $\mathrm{mLW}$ ) level using sea waterand UV-resistant plastic binders. The deployed substrate samples were about $15 \mathrm{~cm}$ in length and fixed every $20 \mathrm{~cm}$ to the rope. All harnesses equipped with the collector samples were hung from the bridge before the spawning time of mussels in mid April to early May 2007 (Pulfrich, 1997), and remained there for 16 months until the mussels were harvested in August 2008.

Samples were retrieved 1 day prior to the start of the testing by lifting the harnesses, including the mussel collectors, by hand to the pavement of the bridge. Collector samples were separated from the rope by cutting the binders and stored dry for $1.5 \mathrm{~h}$ in cool boxes for transportation. Back at the laboratory collector samples were transferred to a seawater recirculation system of about $15^{\circ} \mathrm{C}$ where they stayed until the testing started the following day.

\subsection{Collector materials used}

10 different spat collector materials, both synthetic and natural, were used in this experiment (Table 2). Five of these collectors are patent-registered and are used at commercial mussel cultivation sites in nearshore environments: (1) The Artificial Seaweed (ASW) is a Japanese patent. It consists of a $10 \mathrm{~mm}$ nylon rope as its back bone to which $10 \mathrm{~cm}$ long polypropylene (pp)-leaves are attached perpendicularly at both sites. Each centimetre of back bone holds 20 pp-leaves to enlarge the substrate's surface. (2 and 3) The Christmas Tree Ropes are registered patents in New Zealand. These collectors are used on commercial farms in the Netherlands as well as in New Zealand. The ropes are made from black extruded polypropylene with straight (leaded) or looped appendices of ca. $5 \mathrm{~cm}$ length (LEC, LOC). Both collector types have three strands of lead in their center to support sinking. (4) The Galician Rope (GAR) is patented and produced in Spain. It consists of three nylon-polyethylene (pe) strands added with transversal filaments of the same material and plastic pegs fixed to the center rope every 5 and $25 \mathrm{~cm}$, respectively. (5)The Self-Sinking Collector (SSC) is a Norwegian patent made of polyester net designed as a tube of approx. $3 \mathrm{~cm}$ in diameter. Inside the tube are small stones to ensure sinking. (6) The Ladder (LAD) collector is also a Norwegian patent displaying two $16 \mathrm{~mm}$ thick parallel running pp-ropes, connected to each other every $35 \mathrm{~cm}$ by a plastic bar. With the exception of the GAR which is designed to be used as a single dropper from Galician raft cultures, all other described collector types can be deployed vertically from longline constructions as droppers or looped form end-to-end of the longline as a continuous rope. Additionally, all collector types are known to withstand the mechanical harvesting of either seed or adult mussels and can be reused several times. Two further spat collectors were tested, both consisted of fleece material: (7) Aquamats $^{\circledR}$ (AQU) consists of pp-fleece strands of ca. $30 \mathrm{~cm}$ length ending at a ballast sleeve of the same material. The patented Aquamats ${ }^{\circledR}$ (USA) was originally used for shrimp cultivation. Weights in the ballast sleeve guarantee its use on the bottom of a shrimp tank or pond thereby separating the growing area into smaller compounds. Spatial separation and places to hide for juvenile animals help to decrease stress and adult predation. Aquamats ${ }^{\circledR}$ are a favoured substrate for fouling organisms, a reason for the use of this collector material in this experiment. (8) Another pp-fleece, the Naue ${ }^{\circledR}$ Fleece (NFL), is used to produce, e.g. shore protection bags. These bags are known to be fully covered by different fouling organisms, especially by mussels after a few months $\left(N a u e^{\circledR}\right.$, pers. comm.). The structure of this material is similar to Aquamats ${ }^{\circledR}$ but not as costly. Representative of a natural material (9), a coconut rope (COC) was tested as well. Coconut ropes are used in France for spat collection in the traditional pole ("bouchot") method. Finally, a (10) reference collector (REF) was also suspended in the water. It consists of bushy tufts of an unravelled $10 \mathrm{~mm}$ pp-rope. This collector type has been used in several studies to investigate settlement success of Mytilus larvae (e.g. Alfaro and Jeffs, 2003; Buck, 2007; Walter et al., submitted for publication) and can help to compare the results of this study to other investigations.

The AQU and NFL substrates are fabricated as mats. For the experiments pieces of $15 \mathrm{~cm} \times 10 \mathrm{~cm}$ and $15 \mathrm{~cm} \times 5 \mathrm{~cm}$ were used, respectively. To test the LAD substrate a piece of rope between two pegs was cut out and fixed to the harness. The self-sinking substrate (SSC) was cut in pieces and the two endings of the nylon tube were sealed before fixing the sample to the harness. Like this the woven fabric of SSC did not unravel and stones (helping the substrate to sink) were kept inside the tube. All other substrates were just cut in $15 \mathrm{~cm}$ pieces before they were deployed on the harness ropes. Samples of all substrates were fixed crosswise to the vertically hanging harness ropes. Like this chafing between sample and harness could be reduced and the whole surface of the substrate sample was accessible by mussel larvae.

\subsection{Measurement of current velocity}

Current velocity was measured by using a RCM 7 current meter (Aandera ${ }^{\circledR}$ Instruments), which was deployed in the vicinity of the collectors suspended in the water column. The tidal regime was bidirectional (NNW-SSE) and highest current speeds were measured $3 \mathrm{~h}$ after slack time, independently from seasonal influence. Data were logged for a short time (eight weeks) from 30th August to 25th October 2007.

\subsection{Measurement of dislodgement force on mussel byssus threads}

To measure the dislodgement force a digital force gauge (FH 10 Sauter $^{\circledR}$, Germany) with a sensory range from 0 to $11 \mathrm{~N}$ was deployed, hanging vertically from the top of a wooden frame ( $1 \mathrm{~m}$ in height, Fig. 3a). The force gauge was equipped with a clamp to pull a single mussel (Fig. 3b) from the respective collector, which was mounted at the bottom of the wooden frame on an acrylic glass plate. Data on dislodgement force were recorded by lifting the gauge at a constant and slow velocity using an electric motor until byssus threads or plaques were ruptured. Data were recorded at intervals of 0.1 seconds over the whole dislodgement process. The maximum load of the gauge was limited to $10.5 \mathrm{~N}$ (11 N minus $0.5 \mathrm{~N}$ weight of the clamp). If the maximum value was achieved while dislodgement process was conducted the dislodgement force was denoted as $10.5 \mathrm{~N}$. Once a mussel was fixed to the clamp of the gauge, the dislodgement procedure was started by gently lifting the clamp until single byssus threads were visible (Fig. 3c). The numbers of threads were counted thereafter and the location of the byssus plaque attachment was determined. Byssus attachments were classified into three categories: (1) all byssus attached to the collector surface, (2) byssus threads attached to the shell of other mussels and to the collector substrate and (3) all byssus threads attached to the surface of other mussels. Subsequently, the dislodgement was conducted and the final force measured and recorded. For all three categories approx. 30 mussels were lifted to break the threads.

\subsection{Assessment of substrate microstructure}

To evaluate the appropriateness of the collector surfaces for suitable attachment of byssus plaques, the microstructures of all substrates were investigated using a Scanning Electron Microscope (SEM). First, photos of all collector materials were taken prior to the experiment. All substrates were then exposed for 1-3 weeks below the jetty during the spawning event. Once a week samples of each substrate were taken, dried and examined for post-larval settle- 

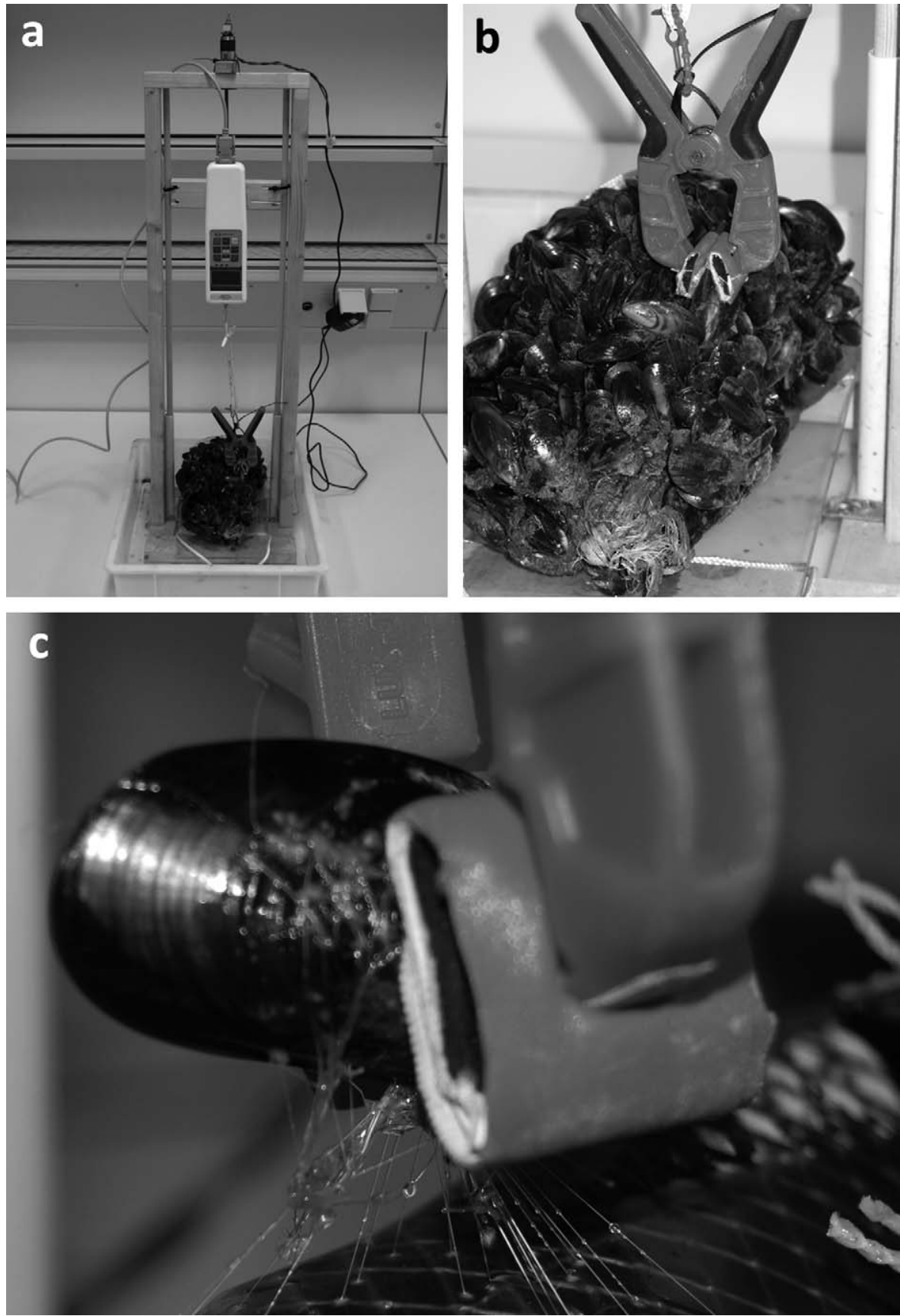

Fig. 3. (a) Dislodgement device with force gauge, (b) sample and clamp to pick up a single mussel showing (c) the number of byssus threads by lifting up the clamp.

ment using a binocular microscope (magnification 50-fold) before SEM photos were taken. Finally, the substrates were dried $(24 \mathrm{~h}$ at $60^{\circ} \mathrm{C}$ ) after the dislodgement experiment and SEM photos were taken of the remaining byssus plagues. For comparability all photos were taken under 100 -fold magnification.

\subsection{Statistical analysis of data}

In this study, data on dislodgement forces were compared between the ten collector types by Kruskal-Wallis one-way ANOVA followed by Dunn's Multiple Comparisons test using the Prism ${ }^{\circledR} 4$ software. Arithmetic mean values and standard deviations were calculated for data on shell morphology (length, width, and height) and byssal numbers as well as for hydrodynamic parameters (current velocity) using MS Excel ${ }^{\circledR} 2007$.

\section{Results}

\subsection{General observations on larval settlement during grow-out}

During the grow-out phase from April 2006 to August 2008 larval settlement was observed and artificial collectors inspected for, e.g. entanglements and abrasions at least once a month. A detailed examination of the substrate-mussel sample was conducted before samples were placed in the dislodgement device. Preliminary observations at this stage were that both fleece-like substrates, AQU and NFL, were fully covered with well attached juvenile mussels ( $\leq 5 \mathrm{~mm}$ ) in late June of the first season, whereas all other substrates (ASW, LEC, LOC, GAR, COC, LAD, REF and SSC) had fewer individuals attached to the surface. Filamentous fringes of the substrates ASW, LEC, LOC, GAR, COC, and REF were partly free of larvae, observed visually. Regarding the rope-like collectors 


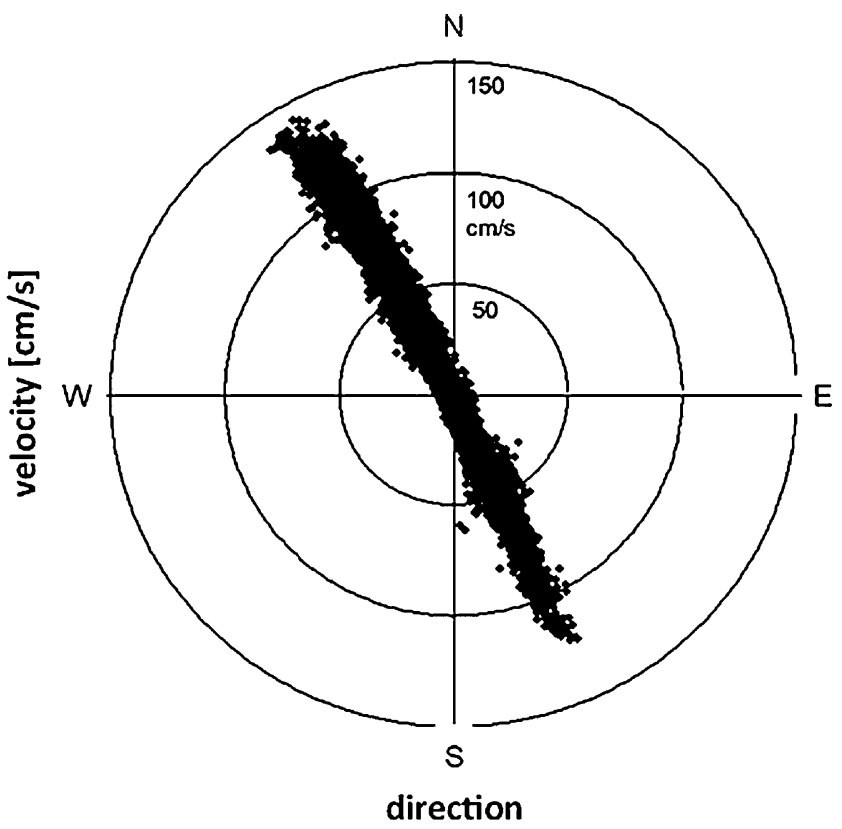

Fig. 4. Direction and velocity of tidal currents in the Jade estuary measured with Aandera RCM7 during 8 weeks from August to October 2007 at the cargo bridge.

(ASW, LEC, LOC, GAR, COC, and REF), all post-larvae settled on or in the vicinity of the central part of the collector, but were equally distributed on fleece (NFL) and on tubular substrates (SSC), however, in the latter case in lower numbers. AQU showed intermediate results due to its slit-like character. Later in the year and especially after the first storm events in autumn, the number of juvenile mussels on fleece and tubular substrates (AQU, NFL and SSC) decreased tremendously, but seemed to stabilize on the filamentous substrates (ASW, LEC, LOC, GAR, and REF). The COC-collector lost most of its filaments during the experiment due to an improper fixation by the plastic binders, resulting in an inaccurate interpretation of the development of post-larval numbers.

In spring 2008, mussels on the filamentous substrates were heavily entangled with the collectors' fringes and formed conglomerated compact units (ASW and GAR). Conglomerates were also built up within the substrate-mussels units on LOC, LEC and REF, but only to a minor extent, due to the short fringes. NFL, LAD and SSC lost most of the mussels and the remaining mussels seemed to migrate to the backbone rope of the harness. However, the loss of mussels was not as strong as on the AQU where the bands of the substrate helped to interweave mussels and substrate.

\subsection{Hydrodynamic conditions}

The current conditions at the cargo bridge in the Jade estuary varied in a diurnal cycle during periods of measurement due to the local tidal regime. The mussels encountered rapid tidal currents flowing in one direction for some hours (S to SE), slowing and stopping at slack tide, and then flowing rapidly in the opposite direction (N-NW). Thus, the cultivated mussels experienced a wide range of current velocities ranging from 0 to $1.42 \mathrm{~m} \mathrm{~s}^{-1}$ (Fig. 4). The mean significant wave height was not measured during the experiment, but should not have exceeded $1.2 \mathrm{~m}$ in height (GKSS, 2006).

\subsection{Morphometric and byssal analysis of M. edulis settling on the collectors}

Mussels harvested at the end of the experiment reached a size of $4.61 \pm 0.28 \mathrm{~cm}(\mathrm{ML} \pm \mathrm{SD})$ in length ranging from 4.12 to $5.08 \mathrm{~cm}, 2.22 \pm 0.15 \mathrm{~cm}(\mathrm{MW} \pm \mathrm{SD})$ in width ranging from 1.93 to
$2.56 \mathrm{~cm}$, and $1.67 \pm 0.13 \mathrm{~cm}(\mathrm{MH} \pm \mathrm{SD})$ in height ranging from 1.42 to $1.93 \mathrm{~cm}(n=35)$.

The number of byssus threads per mussel varied between 13.24 \pm 6.48 SD and 21.17 \pm 4.09 SD. The bars in Fig. 5 show the mean numbers of byssus threads of a single mussel fixed only to the substrate (zone 1), to neighbouring mussels (zone 3 ) or to both (zone 2 ), respectively.

\subsection{Dislodgement force}

The graphs showing dislodgement forces (Fig. 5a) indicate the mean maximum dislodgement-force $[\mathrm{N}]$ per byssus thread and substrate of mussels from zone 1 to 3 . The dislodgement force of mussels from zones 2 and 3 vary around $0.25 \mathrm{~N}$ per thread, while the force per thread of mussels from zone 1 decrease continuously from filamentous substrates with long fringes $(A S W=0.35 \mathrm{~N}$; $\mathrm{GAR}=0.31 \mathrm{~N}$ ), over filamentous substrates with shorter fringes $(\mathrm{LEC}=0.25 \mathrm{~N} ; \mathrm{LOC}=0.25 \mathrm{~N})$, to fleece-like substrates $(\mathrm{NFL}=0.22 \mathrm{~N}$; $\mathrm{AQU}=0.21 \mathrm{~N}$ ) and shows the lowest force for the tubular substrate $(\mathrm{SSC}=0.20 \mathrm{~N}$ ). It can be demonstrated that the substrates with the higher dislodgement values in zone 1 (ASW, COC, GAR, LAD and LEC) exceed their particular value of zone 2 and 3 (except GAR) while at the same time the five substrates with the lower dislodgement value in zone 1 (LOC, REF, NFL, AQU and SSC) are consequently below the respective forces determined for zones 2 and 3 (Fig. 5a). Only a small number of mussels were solely attached to other mussels (zone 3 ) for GAR/LEC/LOC $(n=7 / 4 / 2$, respectively). The standard deviations of each mean force per byssus thread (calculated as maximum forces measured divided by the respective number of threads) is displayed in the table of Fig. 5b.

Significant differences were detected for zone 1 between GAR and REF $(p<0.01)$ and between GAR and AQU $(p<0.05)$. For zone 2 LEC and LOC differed significantly from NFL $(p<0.01$ and 0.05 , respectively). Zone 3 was not tested for differences.

The materials used to fabric the different substrates are displayed in Table 2. The highest dislodgement forces were achieved from substrates made of a mixture of nylon and pp-fibres (ASW), natural fibres (COC) or a mixture of nylon and pe-fibres. These three substrates are followed by the group of collectors fabricated of ppfibres (LAD, LEC, LOC, REF, NFL, and AQU). Lowest dislodgement forces were obtained using polyester fibres (SSC).

\subsection{Microstructure of substrates}

The EM-photos of ASW display a plane surface of the substrate with elongated fissures within the pp leaves (Fig. 6.1a). The mussel post-larva is attached to the substrate's surface without being entangled (Fig. 6.1b). The plague of the byssus thread has full contact to the substrate (Fig. 6.1c). Fig. 6.2a-c shows the slightly rough filaments of the coconut fibre (COC), the attached postlarva and byssus plagues with full contact to the substrate. The plaited filament of GAR is shown as an unused substrate in Fig. 6.3a. Fig. $6.3 \mathrm{~b}$ and c shows the deeply rooted post-larva and the byssus plague with full contact on the relatively rough material profile. Filaments of LAD are displayed in Fig. 6.4a. The attached post-larva of the LAD substrate is shown in Fig. 6.4b and the byssus plague with full contact around a single filament is shown in Fig. 6.4c. Fig. 6.5a-c shows the split filaments of the unused LEC-substrate, the attached post-larva and the byssus plague bridging the split for full contact to the substrate.

Similarly to the leaded rope, LOC filaments are split lengthwise (Fig. 7.1a) and larvae's byssus plague have to bridge the splits for full contact to the substrate (Fig. 7.1c). The REF-substrate is displayed in Fig. 7.2a, with an attached post-larva (Fig. 7.2b) and the byssus plague having full contact around a single filament (Fig. 7.2c). Fig. 7.3a-c shows the very thin and loosely interwoven filaments 
(A)

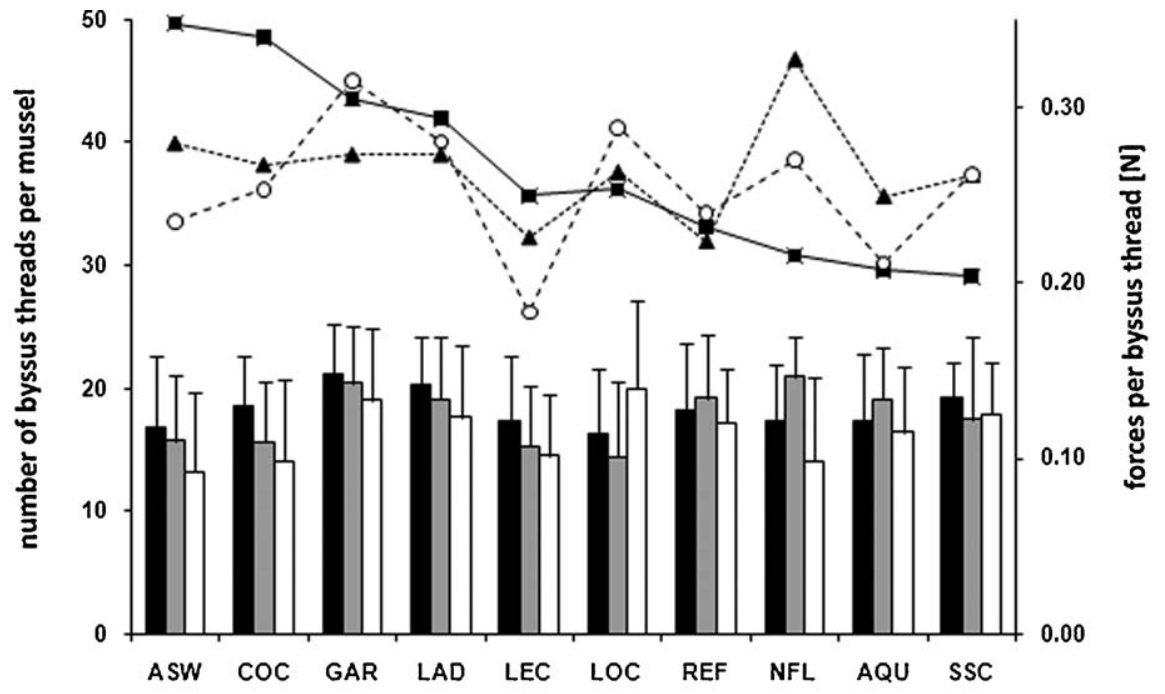

(B)

\begin{tabular}{|c|c|c|c|c|c|c|c|c|c|c|}
\hline & ASW & $\mathrm{COC}$ & GAR & LAD & LEC & LOC & REF & NFL & AQU & SSC \\
\hline \multicolumn{11}{|l|}{ Zone 1} \\
\hline $\begin{array}{l}\text { mean force per } \\
\text { thread [N] }\end{array}$ & 0.35 & 0.34 & 0.31 & 0.29 & 0.25 & 0.25 & 0.23 & 0.22 & 0.21 & 0.20 \\
\hline standard deviation & 0.12 & 0.13 & 0.09 & 0.13 & 0.06 & 0.09 & 0.08 & 0.07 & 0.08 & 0.07 \\
\hline \multicolumn{11}{|l|}{ Zone 2} \\
\hline $\begin{array}{l}\text { mean force per } \\
\text { thread }[N]\end{array}$ & 0.28 & 0.27 & 0.27 & 0.27 & 0.23 & 0.26 & 0.22 & 0.33 & 0.25 & 0.26 \\
\hline standard deviation & 0.08 & 0.10 & 0.10 & 0.11 & 0.06 & 0.09 & 0.08 & 0.10 & 0.12 & 0.12 \\
\hline \multicolumn{11}{|l|}{ Zone 3} \\
\hline $\begin{array}{l}\text { mean force per } \\
\text { thread }[N]\end{array}$ & 0.24 & 0.25 & 0.32 & 0.28 & 0.18 & 0.29 & 0.24 & 0.27 & 0.21 & 0.26 \\
\hline standard deviation & 0.11 & 0.15 & 0.08 & 0.12 & 0.04 & 0.08 & 0.09 & 0.12 & 0.07 & 0.08 \\
\hline
\end{tabular}

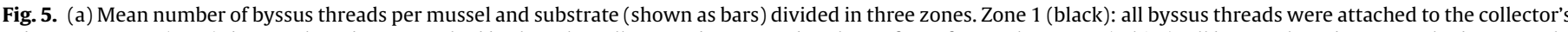

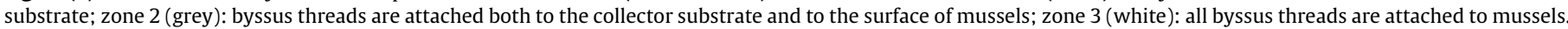

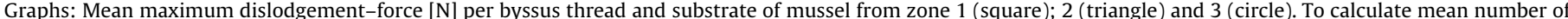

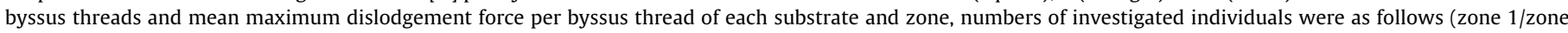

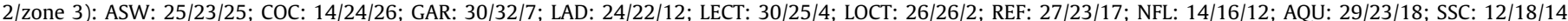

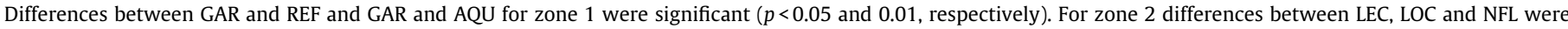

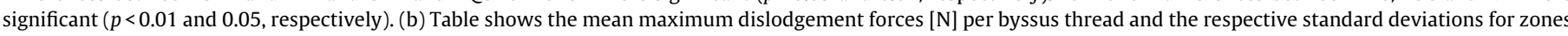
$1-3$.

of NFL as unused substrate (Fig. 7.3a), the deep rooted post-larva (Fig. 7.3b), and three byssus plagues (Fig. 7.3c) with a relatively small contact area to the substrate, due to the felt structure. Likewise NFL, AQU (Fig. 7.4a-c) shows the same felt-like structure of thin and loosely interwoven filaments (Fig. 7.4a), a deeply rooted post-larva (Fig. 7.4b), and byssus plagues not having full contact to the substrate (Fig. 7.4c). The twisted nylon filaments of SSC are shown as unused substrate (Fig. 7.5a), with an attached post-larva (Fig. 7.5b) and the byssus plague on the substrate with full contact (Fig. 7.5c).

With the exception of zone 1 where mussels have only contact to the artificial substrates, mussels build conglomerates by gluing their byssus plagues on the shells of other mussels in their vicinity. Exemplarily, Fig. 8 shows the slightly corrugated surface of a mussel shell with byssus plague attached to it with full contact.

\section{Discussion}

The selection of a suitable site is one of the most important steps toward making a mussel cultivation enterprise profitable, since it is directly linked to the success or failure of a mussel culture business. While site selection depends upon a wide range of criteria, one important parameter is the prevailing hydrodynamic conditions of the local environment. Forces originating from currents, waves, and swell stress the culture candidate as well as the system design and therefore have to be taken into account as an initial consideration. This is especially valid when considering cultivation in high energy environments.

In this study the mechanical forces necessary to dislodge or break byssus threads were investigated. Such research has been thus far concentrated on culture systems situated in protected bays or rias (Lekang et al., 2003; Filgueira et al., 2007) or the applied method produced no comparable data, since attachment strength was tested visually by shacking the collector ropes (Lekang et al., 2003).

The results of our experiment showed that there were at least two main factors affecting the suitability of artificial substrates for the commercially successful cultivation of blue mussels under exposed conditions. First, there were significant differences among the tested collector types regarding the forces necessary to dislodge 

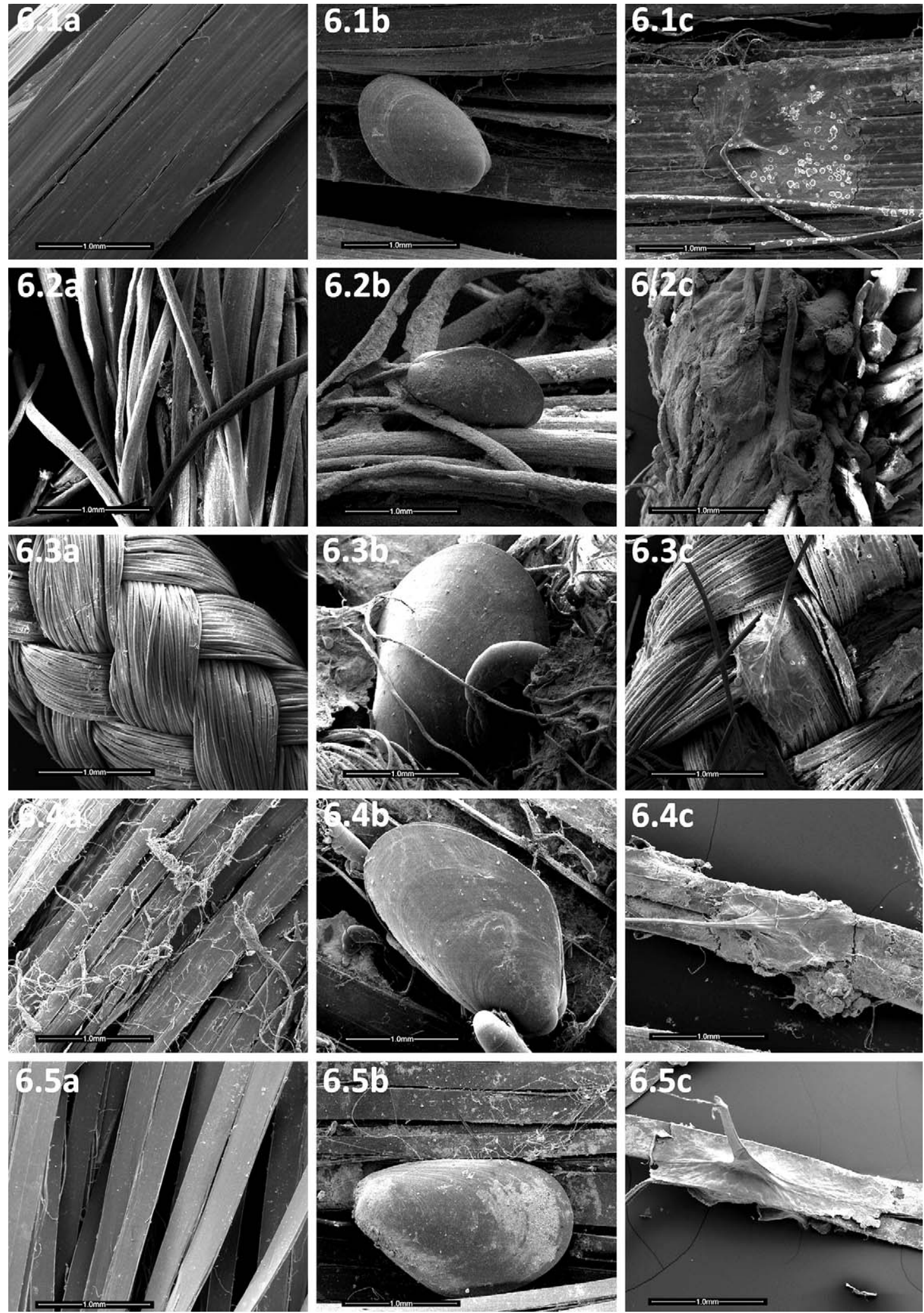

Fig. 6. 1-6.5a-c: EM-photos of (1) ASW, (2) COC, (2) GAR, (3) LAD, and (4) LEC as substrate (a), with attached post-larvae (b) and remaining byssus plagues (c) using 100-fold magnification.

a single mussel from the substrate. Second, there was a difference in the resulting spatial structure of the substrates-mussel conglomerates, according to number, form and length of the substrates' filaments. The latter factor is especially important when mussels grow in various layers around a certain substrate. The longer and more numerous the filaments or appendices of a substrate are, the better the interweaving of mussels with the substrate is even at the outer regions. In the following, we discuss the implications of our experiment in detail and offer advice for substrate development and application for potential farmers. 

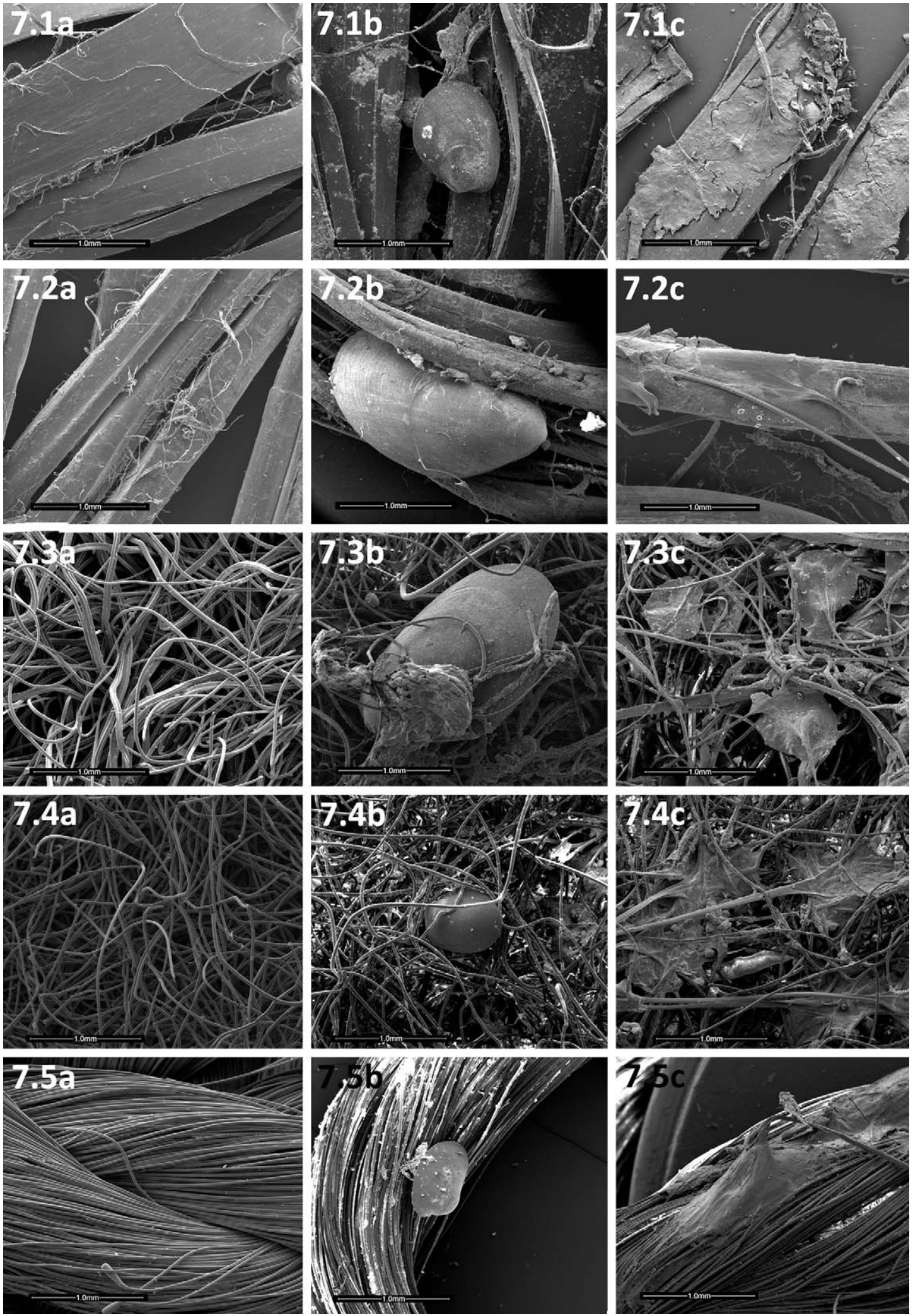

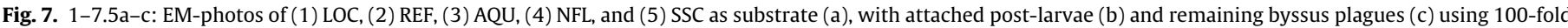
magnification.

\subsection{Attachment to the substrates}

Commercially applied filamentous substrates and natural coconut fibres followed by fleece- or felt-like substrates, provided the best adhesive conditions for mussel attachment to substrates. The tube-like structure of the self-sinking collector provided the weakest adhesive condition. Concerning the materials used to fabric the substrates best adhesive conditions were obtained by 


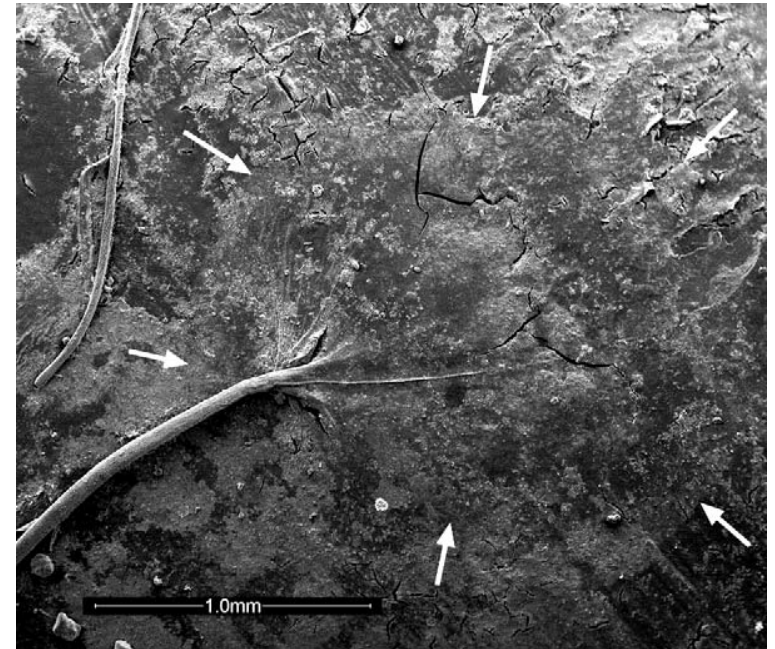

Fig. 8. EM-photo of a byssus plague attached to a mussel shell using 100-fold magnification.

nylon-pe, nylon-pp fabrics or by collectors made of natural fibres. Second best results were achieved by the group of substrates made off pp-fibres. The weakest attachment was measured using polyester as substrate material.

Interestingly, the dislodgement forces for the best four substrates were even higher than for mussel shells, which represent the natural substrate of M. edulis. The SEM photos (Figs. 6 and 7) of byssus plagues show full contact on or around the more or less plane surfaces of the filamentous substrates. In contrast byssus plagues on fleece substrates had only partial contact to the thin filaments. Most of the potential contact area is needed to bridge gaps between the filaments. Further, fleece filaments are only interwoven, not welded or glued together. It was observed that the impinging forces on mussels and their plagues dissociate the respective filaments from the fleece fabric, thus decreasing the foothold of the mussel. Dislodged mussels from fleece substrates were observed having remains of fleece filaments on the plagues of the byssus threads. All filamentous substrates still had numerous adult mussels after 16 months of exposure (Brenner, unpublished data), whereas the mat-like fleece (NFL) and the tubular SSC lost most of their mussel load. These findings have important implications for cultivation management, since different substrates should be used according to the desired product (seed or market sized mussels), or depending on the type of cultivation approach (one or two step). The filamentous substrates build strongly interwoven conglomerates with the mussels. Depending on the length of appendices and their number per cm collector length, even mussels from the outer region of the conglomerate had contact to the substrate in the centre. In contrast spatially unstructured substrates provide fixation only for mussels close to the inner part of the artificial substrate. This can be explained by the fact that mussel conglomerates on collectors are multi-layered, leading to a different attachment degree of mussels. While mussels in the central region of the collector are all attached to the substratum, individuals in the periphery are only attached to their neighbouring mussels or only partly attached to the substrate. The same results were observed in the central and peripheral regions in mussel beds by Dayton (1973) and Witman and Suchanek (1984). These studies showed that mussels attached to conspecifics were more easily dislodged than those attached directly to the substratum. On the other hand, mussels in the outer regions are more exposed to high energy conditions in the currents, waves and swell, which should stimulate the build up of a higher number and more stable threads. However, our experiment show in concordance with other scholars, that the shells of the mussels in the periphery were more overgrown by epiphytes (e.g. barnacles, polychaetes, bryozoans) and therefore experienced more forces than their neighbouring mussels in the central part of the conglomerates (Witman and Suchanek, 1984).

Interestingly, the settlement of post-larvae on the substrate differed from the settlement of juvenile or adult mussels. In early summer fleece-like substrates were covered with small larvae ( $\geq 5 \mathrm{~mm}$ ) (Brenner, unpublished data). In the beginning of the settlement process, drag force on larvae should be low, since they were deeply rooted into the fleece substrates. These results correspond only with the first part of the primary/secondary settlement model of Bayne (1964), postulating a preference of mussel larvae for filamentous substrates. The loss of juvenile mussels later in the year due to a second larval phase seems, however, not likely since the loss of mussels occurred in August to September, where mussels are already too big in size for a second larval phase. Once they grow in length and weight, drag increases (Harger, 1970). By autumn fleece substrates had already lost most of their mussels. On filamentous substrates fewer post-larvae were found in the beginning of settlement process, and were oriented towards the core of the substrate. While growing over time the mussels grip themselves by interweaving with the long appendices of the substratum. By this behaviour the loss of mussels appeared to be diminished and numbers of settled mussels seem to be rather stable.

With the experimental approach deployed in this study the influence of the different materials used to fabric the substrates cannot fully be clarified. However, it is noticeable that best adhesive conditions were provided using nylon and natural fibres for the fabrication of the substrates. Second best conditions were provided using pp-fibres. Whether polyester is generally unsuitable for mussels as substrate material, since lowest dislodgement values were measured using this material, should be clarified in further studies.

\subsection{Mussels experiencing hydrodynamic forces}

In this study we have shown which forces are necessary to artificially detach mussels from the substrates' surface. In doing so byssus threats attached to either the collector or to other mussels or a combination of both were investigated. However, at exposed sites more factors generating forces act on the body of blue mussels as well as on their shape and their attachment. These forces include current velocities, waves, and swell as well as forces resulting from bio-pumping and their own growing size and overgrowing fouling organisms, leading to an enlarged surface area and thus increasing the forces acting on the individual mussel. While mussels have the ability to adapt their attachment strategy according to these changes Witman and Suchanek (1984) measured a 15 times higher attachment strength of mussels living in exposed vs. protected habitats. Several studies have suggested that mussels go "with the flow", producing more byssal threads that increase attachment strength when higher water velocities are encountered (Price, 1982; Bell and Gosline, 1997; Carrington, 2002). However, Moeser et al. (2006) relativised this general conclusion and stated a hindered thread production at water velocities above $18 \mathrm{~cm} / \mathrm{s}$. In our experiment the measured current velocities were approx. 7 times higher (up to $1.4 \mathrm{~m} / \mathrm{s}$ ) and mussels were not dislodged and continued producing threads.

Taking into account that in this study no single mussel but in fact mussel conglomerates experience forces, we suggest that forces on the clusters of organisms will be smaller than the total force on all solitary individuals in sum (Johnson, 2001; Vogel, 1984). Forces will decrease with increasing cluster density. In our experimental cultures collectors floating below the cargo bridge created an artificial vertical mussel bed that certainly further reduced flow and therefore the impact of drag at least on the more centrally grow- 
ing mussels. The low resistance against dislodgement or breaking forces of mussels growing in aggregations versus those growing individually is probably balanced by a neighbourhood protection against the full impact of currents (Buck and Buchholz, 2005).

To get an insight about forces affecting mussel conglomerates it is important to know that these forces also act on the entire collector which is going with the flow too. It would be necessary to examine drag and lift as well as the acceleration reaction for mussels, mussel conglomerates and for full collectors also. As these data could not be obtained in this study we cannot go in more detail with the forces impacting on mussels and the collector.

\subsection{Implications for mussel farming at exposed sites}

Artificial substrates for spat collection in exposed or offshore sites must combine different properties. Due to the distance to other adjacent wild populations larval concentration in the water column is probably low in offshore areas (Walter et al., submitted for publication). Therefore, deployed substrates must be highly attractive for remaining mussel larvae. Furthermore, substrates must hinder dislodgement of growing juvenile mussels by strong currents and waves. Considering options such as whether to produce either seed or market sized mussels or taking a thinning step during the grow-out if numbers of settled post-larvae are high, different scenarios of deployed substrates are possible. If the production of seed mussels is intended, substrates with a high fleece percentage and only short but numerous appendices are required. The harvesting of seed mussels should be organized before mussels achieve a growth bigger than approx. $1-2 \mathrm{~cm}$ and before the storm season begins. In contrast, if market sized mussels are required, fleece percentage should be reduced around the core of a collector rope and appendices should be long and numerous allowing the possibility to build up strong interwoven mussel-substrate conglomerates, able to survive winter storm events without bigger losses of mussels. A combination of both collector types might be suitable if settlement success is high and a thinning step during grow-out is possible or necessary. In this case the collector of choice for the first step would be a fleece-like and after the thinning a filamentous substrate with long appendices. This scenario would also be suitable for a combined production of seed and market sized mussels.

\section{Conclusions and outlook}

In this study evidences were achieved that the surface properties relevant for the adhesive conditions are influenced by the materials used for the fabrication of the substrate. More important, however, seems to be the emerging spatial structure of a substrate with its appendices building up conglomerates together with the settled mussels. Substrates designed for the exposed and offshore application should have a strong core, coated with a fleece-like material for larval attraction, combined with numerous well-fixed appendices which secure even big juvenile mussels by building a strong conglomerate of substrate and mussels. Depending on the type of mussel cultivation desired, such as production of either seed or market sized mussels, percentages of fleece and number and length of appendices can vary.

\section{Acknowledgments}

The authors are grateful to the Niedersachsen Port Authorities (NPorts) who generously allowed us to use the cargo bridge at the Jade estuary for deploying the mussel collectors. We would also like to thank André Pechura who set up the dislodgement device and to Christian Wilhelm for his substantial support in the lab. This work was realised within the project FV 168 MytiFit financed by the Alfred Wegener Institute for Polar and Marine Research, Bremerhaven (Germany) and the Ministry of Construction, Environment, Traffic and Europe of the Federal State of Bremen, Bremen (Germany).

\section{References}

Alfaro, A.C., Jeffs, A.G., 2003. Variability in mussel settlement on suspended ropes placed at Ahipara Bay, Northland, New Zealand. Aquaculture 216, 115-126.

Alfaro, A.C., Copp, B.R., Appleton, D.R., Kelly, S., Jeffs, A.G., 2006. Chemical cues promote settlement in larvae of the green-lipped mussel Perna canaliculus. Aquac. Int. $14,405-412$.

Alfred, N., Ista, L.K., Callow, M.E., Callow, J.A., Lopez, G.P., Clare, A.S., 2005. Mussel (Mytilus edulis) byssus deposition in response to variations in surface wettabillity. J. R. Soc. Interf. 3 (6), 37-43.

Bayne, B.L., 1964. Primary and secondary settlement in Mytilus edulis L. (Mollusca) J. Anim. Ecol. 33, 513-523.

Becker, G., Dick, S., Dippner, J., 1992. Hydrography of the German Bight. Mar. Ecol. Prog. Ser. 91, 9-18.

Bell, E.C., Gosline, J.M., 1997. Strategies for a life in flow: tenacity, morphometry, and probability of dislodgement of two Mytilus species. Mar. Ecol. Prog. Ser. 159, 197-208.

Bomo, A.M., Stevik, T.K., Myklebust, H., 1998. Development of technology for Norwegian shellfish production. ITF-report 96.

Bridger, C.J., Costa-Pierce, B.A., 2003. Open Ocean Aquaculture: From Research to Commercial Reality. The World Aquaculture Society, Baton Rouge.

Buck, B.H., 2007. Experimental trials on the feasibility of offshore seed production of the mussel Mytilus edulis in the German Bight: installation, technical requirements and environmental conditions. Helgol. Mar. Res. 61, 87-101.

Buck, B.H., Buchholz, C.M., 2005. Response of offshore cultivated Laminaria saccharina to hydrodynamic forcing in the North Sea. Aquaculture 250, 674691.

Buck, B.H., Krause, G., Rosenthal, H., 2004. Multifunctional use, environmental regulations and the prospect of offshore co-management: potential for and constraints to extensive open ocean aquaculture development within wind farms in Germany. Ocean Coast. Manage. 47, 95-122.

Buck, B.H., Krause, G., Michler-Cieluch, T., Brenner, M., Buchholz, C.M., Busch, J.A., Fisch, R., Geisen, M., Zielinski, O., 2008. Meeting the quest for spatial efficiency: progress and prospects of extensive aquaculture within offshore wind farms. Helgol. Mar. Res. 62, 269-281.

Bucklin, A., Howell, W.H., 1998. Progress and prospects from the UNH Open Ocean Aquaculture Demonstration Project. In: Stickney, R.R. (Ed.), Joining Forces with Industry. Proceedings of the Third International Conference of Open Ocean Aquaculture. Corpus Christi, TX, US, 10-15 May, pp. 7-30.

Carrington, E., 2002. Seasonal variation in the attachment strength of blue mussels: causes and consequences. Limnol. Oceanogr. 47, 1723-1733.

Connell, J.H., 1985. The consequences of variation in initial settlement vs. post settlement mortality in rocky intertidal communities. J. Exp. Mar. Biol. Ecol. 93, $11-45$.

CWSS, 2008. Nomination of the Dutch-German Wadden Sea as World Heritage Site, vol. 1. Common Wadden Sea Secretariat, Wilhelmshaven, Germany.

Dayton, P.K., 1973. Competition, disturbance, and community organisation: the provision and subsequent utilisation of space in a rocky intertidal community. Ecol. Monogr. 41 (4), 351-389.

Eckman, J.E., 1987. The role of hydrodynamics in recruitment, growth, and survival of Argopecten irradiands (L.) and Anomia simplex (D'Orbigny) within eelgrass meadows. J. Exp. Mar. Biol. Ecol. 106, 165-191.

Filgueira, R., Peteiro, L.G., Labarta, U., Fernandez-Reiriz, M.J., 2007. Assessment of spat collector ropes in Galician mussel farming. Aquac. Eng. 37, 195-201.

Frandsen, R.P., Dolmer, P., 2002. Effects of substrate type on growth and mortality if blue mussels (Mytilus edulis) exposed to the predator Carcinus meanas. Mar. Biol. 141, 253-262.

GKSS, 2006. GKSS Research Centre Geesthacht, CoastDat database, http://www.coastdat.de/data/index.html.de, assessed in May 2009.

Guiñez, R., 2005. A review on self-thinning in mussels. Rev. Biol. Mar. Oceanogr. 40 $1-6$.

Guiñez, R., Castilla, J.C., 1999. A tridimensional self-thinning model for multilayered intertidal mussel. Am. Nat. 153, 341-357.

Hansen, D.C., Waite, J.H., 1991. Marine Metal Chelating Proteins. College of Marine Studies, University of Delaware, American Chemical Society, Lewes.

Harger, J.R.E., 1970. The effect of wave impact on some aspects of the biology of mussels. Veliger 12, 401-414.

Hickman, R.W., 1992. Mussel Cultivation. In: Gosling, E. (Ed.), The Mussel Mytilus: Ecology, Physiology, Genetics and Culture. Development in Aquaculture and Fisheries Science no. 25. Elsevier, Amsterdam, pp. 465-510.

Johnson, A.S., 2001. Drag, drafting, and mechanical interactions in canopies of the red alga Chondrus crispus. Biol. Bull. Mar. Biol. Lab. 201 (2), 126-135.

Kleinsteuber, H., Will, R., 1988. Populationsdynamik der Miesmuschel und Entwicklung der Miesmuschel in den Wattgebieten der Nordsee unter besonderer Berücksichtigung der niedersächsischen Küste. Landesfischereiverband WeserEms e.V., Oldenburg, Germany.

Korringa, P., 1976. Farming Marine Organisms low in the Food Chain: A Multidisciplinary Approach to Edible Seaweed, Mussel and Clam Production 
Developments in Aquaculture and Fisheries. Science 1, Elsevier, Amsterdam, Netherlands, $224 \mathrm{pp}$.

Langan, R., Horton, F., 2003. Design, operation and economics of submerged longline mussel culture in the open ocean. Bull. Aquac. Assoc. Can. 103, 11-20.

Lekang, O.-I., Stevik, T.K., Bomo, A.M., 2003. Evaluation of different combined collectors used in longlines for blue mussel farming. Aquac. Eng. 27 (3), 89-104.

McShane, P.E., Nylor, J.R., 1995. Depth can affect post-settlement survival of Halotis iris (Mollusca: Gastropoda). J. Exp. Mar. Biol. Ecol. 187, 1-12.

Moeser, G.M., Leba, H., Carrington, E., 2006. Seasonal influence of wave action on thread production in Mytilus edulis. J. Exp. Biol. 209, 881-890.

Moreno, C.A., 1995. Macroalgae as a refuge from predation for recruits of the mussel Chloromytilus chorus (Molina, 1782) in Southern Chile. J. Exp. Mar. Biol. Ecol. 191, 181-193.

Morrisey, D.J., Cole, R.G., Davey, N.K., Handley, S.J., Bradley, A., Brown, S.N., Madarasz, A.L., 2006. Abundance and diversity of fish on mussel farms in New Zealand. Aquaculture 252, 277-288.

Nishida, A., Ohkawa, K., Ueda, I., Yamamoto, H., 2003. Green mussel Perna vividis L.: attachment behavior and preparation of antifouling surfaces. Biomol. Eng. 20, 381-387.

Price, H.A., 1982. An analysis of factors determining seasonal variation in the byssal attachment strength of Mytilus edulis L. J. Mar. Biolog. Assoc. U.K. 62, 147-155.

Pulfrich, A., 1997. Seasonal variation in the occurrence of planktonic bivalve larvae in Schleswig-Holstein Wadden Sea. Helgol. wissenschaftl. Meeresunters. 51, 23-39.

Ryan, J., 2005. Offshore aquaculture-do we need it, and why is it taking so long? International Salmon Farmers Association (Ireland). In: Expert workshop on sustainable aquaculture, DG JRC European Commission, Institute for Prospective Technological Studies, 17-18 January 2005, Seville, Spain.

Schiel, D.R., 2004. The structure and replenishment of rocky shore intertidal communities and biogeographic comparisons. J. Exp. Mar. Biol. Ecol. 300, 309-342.

Seaman, M.N.L., Ruth, M., 1997. The molluscan fisheries of Germany. NOAA Technical Reports NMFS 129, 57-84.

Smaal, A.C., 2002. European mussel cultivation along the Atlantic coast: production status, problems and perspectives. Hydrobiologia 484, 89-98.

Stickney, R.R., 1998. Joining forces with industry-open ocean aquaculture. In: Proceedings of the 3rd Annual International Conference, 10-15 May, Corpus Christi, Texas, TAMU-SG-99-103, Corpus Christi, Texas Sea Grant College Programme.

Vogel, S., 1984. Drag and flexibility in sessile organisms. Am. Zool. 24 (1), 3744.

Walter, U., Liebezeit, G., 2001. Nachhaltige Miesmuschel-Anzucht im niedersächsischen Wattenmeer durch die Besiedlung natürlicher und künstlicher Substrate. Forschungszentrum Terramare, Wilhelmshaven, Germany. Abschlussbericht der ersten Projektphase, 98 pp.
Walter, U., Liebezeit, G., 2003. Efficiency of blue mussel (Mytilus edulis) spat collectors in highly dynamic tidal environments of the Lower Saxonian coast (southern North Sea). Biomol. Eng. 20, 407-411.

Walter, U., Buck, B.H., Liebezeit, G. submitted for publication. Larval occurrence and settlement in the German Bight: a trial to estimate potentials for Mytilus edulis culture in offshore areas. Aquac. Int.

Walters, L.J., Wethey, D.S., 1996. Settlement and early post-settlement survival of sessile marine invertebrates on topographically complex surfaces: importance of refuge dimensions and adult morphology. Mar. Ecol. Prog. Ser. 137, 161-171. Witman, J.D., Suchanek, T.H., 1984. Mussels in flow: drag and dislodgement by epizoans. Mar. Ecol. Prog. Ser. 16, 259-268.

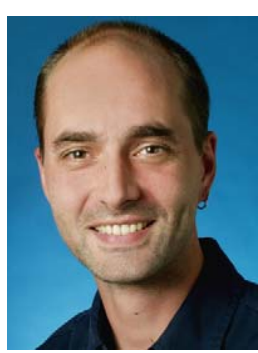

M. Brennerwas born in Kaiserslautern RhinelandPalatine. He studied marine biology at the University of Freiburg, Bremen and at the Center for Tropical Marine Ecology (ZMT) in Bremen (all in Germany). Onwards, he worked in projects concerning the multifunctional use of offshore wind farms and open ocean aquaculture in the North Sea for the Alfred Wegener Institute for Polar and Marine Research (AWI) in Bremerhaven (Germany). Between, 2005-2009 he was a PhD candidate at the AWI and the Jacobs University of Bremen studying the potentials of offshore sites for mussel cultivation. Today, Matthias Brenner is working at the IMARE (Institute for Marine Resources)/Section Blue Bioindustry in Bremerhaven.

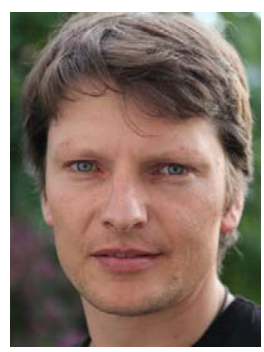

B.H. Buck was born in Mülheim/Ruhr in North-Rhine Westphalia. He studied marine biology at the University of Bremen, at the Institute for Marine Research in Kiel, at the ZMT in Bremen (all in Germany) and at the James Cook University in Townsville (Australia). In 2004 he finished his PhD at the Alfred Wegener Institute for Polar and Marine Research (AWI) and the University of Bremen on offshore aquaculture technology, biology, legislation and integrated coastal zone management. Since July 2007, he was given a cooperation professorship for "Applied Marine Biology" at the University of Applied Sciences in Bremerhaven and the AWI. Today, Bela H. Buck is in the Directory Board of the IMARE (Institute for Marine Resources) which mainly focuses on applied marine sciences. 